\section{Thiopentone pretreatment for propofol injection pain in ambulatory patients}

Richard D. Haugen MD, Himat Vaghadia MD FRCPC MHSc, Terry Waters MD, Pamela M. Merrick BSN
This study investigated propofol injection pain in patients undergoing ambulatory anaesthesia. In a randomized, doubleblind trial, 90 women were allocated to receive one of three treatments prior to induction of anaesthesia with propofol. $\mathrm{Pa}$ tients in Group $C$ received $2 \mathrm{ml}$ normal saline, Group $L, 2$ $\mathrm{ml}$, lidocaine $2 \%$ (40 mg) and Group T, $2 \mathrm{ml}$ thiopentone $2.5 \%$ (50 mg). Venous discomfort was assessed with a visual analogue scale (VAS) 5-15 sec afier commencing propofol administration using an infusion pump (rate $1000 \mu \mathrm{g} \cdot \mathrm{kg}^{-1} \cdot \mathrm{min}^{-1}$ ). Lass of consciousness occurred in 60-90 sec. Visual analogue scores (mean $\pm S D$ ) during induction were lower in Groups $L$ (3.3 $\pm 2.5)$ and $T$ (4.1 \pm 2.7$)$ than in Group $C$ (5.6 \pm 2.3$) ; P$ $=0.0031$. The incidence of venous discomfort was lower in Group L (76.6\%; $P<0.05)$ than in Group $C(100 \%)$ but not different from Group $T(90 \%)$. The VAS scores for recall of pain in the recovery room were correlated with the VAS scores during induction ( $r=0.7045 ; P<0.0001)$. Recovery room discharge times were similar: $C(75.9 \pm 19.4 \mathrm{~min}) ; L 73.6 \pm$ $21.6 \mathrm{~min}) ; T(77.1 \pm 18.9 \mathrm{~min})$. Assessing their overall satisfaction, $89.7 \%$ would choase propofol anaesthesia again. We conclude that lidocaine reduces the incidence and severity of propofol injection pain in ambulatory patients whereas thiopentone only reduces its severity.

\section{Key words}

ANAESTHETICS, INTRAVENOUS: propofol, thiopentone; COMPLICATIONS: venous pain;

ANAESTHESIA: ambulatory.

From the Division of Ambulatory Anaesthesia, Department of Anaesthesia, Vancouver Hospital and Health Sciences Centre, University of British Columbia, Faculty of Medicine, Room 3200,910 West 10th Avenue, Vancouver, BC, Canada VSZ 4A3.

Address correspondence to: Dr. Himat Vaghadia, Department of Anaesthesia, Vancouver Hospital and Health Sciences Centre, University of British Columbia, Faculty of Medicine, Room 3200, 910 West 10th Avenue, Vancouver, BC Canada V5Z 4A3.

Presented in part at the 9th Annual Meeting of the Society of Ambulatory Anesthesia, 1994, Chicago, Illinois.

Accepted for publication 1st August, 1995.
Cette étude évalue la douleur à l'injection du propofol en anesthésie ambulatoire. Au cours d'une étude randomisée et à double aveugle, 90 sujets du sexe féminin sont répartis en trois groupes. Au moment de linduction, les patients du groupe $C$ reçoivent $2 \mathrm{ml}$ de soluté physiologique, celles du groupe $L, 2$ $\mathrm{ml}$ de lidocaüne (40 $\mathrm{mg}$ ), et celles du groupe $T, 2 \mathrm{ml}$ de thiopentone $(50 \mathrm{mg})$. La douleur à l'injection est évaluée sur une échelle visuelle analogique (EVA), 5-15 sec après le début de l'administration du propofol avec une pompe à perfusion (vitesse $1000 \mu \mathrm{g} \cdot \mathrm{kg}^{-1} \cdot \mathrm{min}^{-1}$ ). La perte de conscience survient en 60-90 sec. Les scores sur l'EVA pendant linduction sont plus bas dans les groupe $L(3,3 \pm 2,5)$ et $T(4,1 \pm 2,7)$ que dans le groupe $C(5,6 \pm 2,3) ; P=0,0031)$. Lincidence de la douleur est plus basse dans le groupe $L(76,6 \% ; P<0,05)$ que dans le groupe $C(100 \%)$ mais n'est pas différente dans le groupe $T$ (90\%). Les scores sur l'EVA pour l'évocation douloureuse sont en corrélation avec les scores enregistrés à l'induction ( $r=0,704 \dot{5} ; P<0,0001$ ). La durée du séjour en salle de réveil est la même pour les trois groupes: $C$ (75,9 $\pm 19,4$ min); $L(73,6 \pm 21,6 \mathrm{~min}) ; T(77,1 \pm 18,9 \mathrm{~min})$. En ce qui concerne la satisfaction générale, $89,7 \%$ des patientes choisiraient de nouveau l'anesthésie au propofol. Les auteurs conchuent que la lidocaüne diminue l'incidence et lintensité de la douleur à linjection du propofol alors que le thiopentone n'en réduit que l'intensité.

Intravenous administration of propofol is associated with a high incidence of venous pain and discomfort. ${ }^{1}$ Venous pain occurs in $45-100 \%$ of patients when veins on the dorsum of the hand are utilized for drug injection. ${ }^{1-5} \mathrm{Li}$ docaine is frequently administered prior to propofol to diminish venous discomfort. ${ }^{1,3}$

Recently, it has been demonstrated that pre-treatment with thiopentone $(100 \mathrm{mg})$ was more effective than lidocaine $(20 \mathrm{mg})$ in reducing the incidence of propofol injection pain, ${ }^{5}$ but this has not been confirmed. In addition, thiopentone pre-administration may not be suitable in ambulatory patients due to the possibility of delayed recovery. The aim of this study was to compare thiopentone with lidocaine for the prevention of propofol injection pain in ambulatory patients. 


\section{Methods}

After receiving institutional Ethics Committee approval, 90 healthy women aged 15-34 yr undergoing daycare gynaecological surgery were enrolled prospectively in the study. Patients received a verbal and written description of the study and gave written informed consent to participate. Consent from minors was obtained in accordance with the institutional policy and was acceptable to the Ethics Committee. All but four underwent therapeutic abortions and the others had fractional dilatation and curettage.

Sedative premedications were not given. Fatients had a $20-G$ intravenous cannula inserted into the dorsum of the hand, without local anaesthetic, as is customary in our unit. We recorded the hand in which the cannula was placed. An intravenous solution of $2 / 35 \%$ dextrose - $1 / 3$ normal saline was started. Patients were randomly assigned to receive one of three pre-treatments $30 \mathrm{sec}$ before induction of anaesthesia with propofol: $\mathrm{C}=$ control group received $2 \mathrm{ml}$ normal saline, $\mathrm{L}=$ lidocaine group received $2 \mathrm{ml}$ lidocaine $2 \%$ and $\mathrm{T}=$ thiopentone received $2 \mathrm{ml}$ thiopentone $25 \%$. The drug doses chosen were based on previous studies. ${ }^{1,5}$ All test solutions were at room temperature. Patient recruitment and preparation of blinded treatment syringes were done by one investigator (RH). The syringes were blinded with pink opaque tape. Patients were taken to the operating room where an anaesthetist, blinded to the group assignment, applied monitors and familiarized the patient with use of a Visual Analog Scale (VAS) ruler. The VAS ruler had a scale from 0 to $10 \mathrm{~cm}$ on one side and no markings on the patient side. A baseline VAS score was not done because all patients were instructed that the pain score using the VAS ruler would be recorded during administration of propofol. All medications were delivered through the injection port nearest to the cannula (total deadspace $=$ $1.0 \mathrm{ml}$ ). The treatment syringe was administered and 30 sec later a bolus dose of $2.5 \mathrm{mg} \cdot \mathrm{kg}^{-1}$ propofol was administered using the bolus function of a BARD ${ }^{\circledR}$ INFUS OR infusion pump $\left(1000 \mu \mathrm{g} \cdot \mathrm{kg}^{-1} \cdot \mathrm{min}^{-1}\right)$. The room temperature was $16-20^{\circ} \mathrm{C}$. All the patients had their intravenous infusions fully open and opioids were not given before induction of anaesthesia. Five to $15 \mathrm{sec}$ after the propofol bolus was started, a VAS score of venous discomfort was assessed (OR-VAS) when the patient experienced pain. ${ }^{2}$ Patients were also asked to describe their pain using a verbal rating scale (none, mild, moderate or severe (OR-VRS)). Loss of consciousness took 60-90 sec. After induction, anaesthesia was continued using oxygen and nitrous oxide $(66 \%)$ and propofol infused at $0-200 \mu \mathrm{g} \cdot \mathrm{kg}^{-1} \cdot \mathrm{min}^{-1}$ titrated to effect.

In the Post-Anaesthesia Recovery Room (PAR), 30 min after patients had recovered consciousness, a PAR nurse blinded to treatment asked whether the patients recalled receiving medications during induction of anaesthesia and whether there was any recall of venous discomfort. If discomfort was recalled, patients were asked to use the VAS scale to describe their pain recalled from the time of induction (PAR-recall VAS). Patients were also asked to choose between five terms (burning, stinging, minor ache, tingling and squeezing) to describe the discomfort. Routine PAR admission and discharge times were recorded for each patient, and prior to discharge each patient was asked "Would you have propofol again?"

Age was analyzed for between-group differences using the Kruskal-Wallis test. Weight, OR-VAS, PAR-recall VAS and PAR discharge time were analyzed using oneway ANOVA with Student-Newman-Keuls test for posthoc comparisons. The PAR-VAS scores were condensed to yes/no categories due to an excessive number of zero values and were analyzed using a Chi-square test. Categorical variables were analyzed using Chi-square or Fisher's exact tests as appropriate; i.e., ASA score, recall of medication, recall of pain, OR-VRS, PAR-VAS, type of pain and patient's acceptance of propofol - yes/no. $P<0.05$ was considered significant except where Bonferroni's correction was applied to contingency tables of pair-wise comparisons after an overall Chi-square.

\section{Results}

All three groups were comparable with regard to demographics (Table I). The incidence of pain on induction (OR-VRS) was lower in the lidocaine group than in the control group (Table II). The VAS rating of pain during induction (OR-VAS) and its recall in the recovery room (PAR-recall VAS) are summarized in Table III. Both lidocaine and thiopentone groups experienced less pain during induction than the control group $(P<0.05)$.

In the PAR, $13.3 \%, 36.7 \%$ and $26.7 \%$ did not recall venous discomfort in the control, lidocaine and thiopentone groups respectively. For all patients, recall of pain was higher among those who experienced pain during induction $(P<0.0001$, Table IV). The recalled VAS was correlated with the VAS during induction $(r=0.7045$, $\mathrm{r}^{2}=0.4886, P<0.0001$ ). Among those with pain during induction, the incidence of recall was $87 \%, 76 \%$ and $79 \%$ for control, lidocaine and thiopentone respectively $(P=$ 0.5704). Description of pain recalled was also not different among groups. Mean PAR discharge times ( $\pm S D$ ) were not different among groups: control $=75.9 \pm 19.4$ $\mathrm{min}$, lidocaine $=73.6 \pm 21.6 \mathrm{~min}$ and thiopentone $=$ $77.1 \pm 18.9 \mathrm{~min}$. Responses to the question "Would you have propofol again?" showed that, overall, $89.7 \%$ said "yes" with no difference among the three groups: $89.3 \%$, 
TABLE I Patient demographic data

\begin{tabular}{lllll}
\hline & $\begin{array}{l}\text { Control } \\
(n=30)\end{array}$ & $\begin{array}{l}\text { Lidocaine } \\
(n=30)\end{array}$ & $\begin{array}{l}\text { Thiopentone } \\
(n=30)\end{array}$ & $P$ \\
\hline Age (yr) median (range) & $26.5(16-54)$ & $25.5(15-49)$ & $25.5(17-48)$ & NS \\
Weight (kg) mean \pm S.D. & $59.6 \pm 9.0$ & $57.1 \pm 10.4$ & $62.7 \pm 13.1$ & NS \\
Hand used & 13.3 & 10.0 & 13.3 & NS \\
- L (\%) & 86.7 & 90.0 & 86.7 & NS \\
- R (\%) & & & & NS \\
ASA status & 50.0 & 43.3 & 40 & \\
$-1(\%)$ & 50.0 & 56.7 & 56.7 & \\
$-2(\%)$ & 0.0 & 0.0 & 3.3 & \\
$-3(\%)$ & & & & \\
\hline
\end{tabular}

TABLE II Incidence of pain during propofol induction (Verbal Rating Scale)

\begin{tabular}{llll}
\hline & $\begin{array}{l}\text { Control } \\
(n=30)\end{array}$ & $\begin{array}{l}\text { Lidocaine } \\
(n=30)\end{array}$ & $\begin{array}{l}\text { Thiopentone } \\
(n=30)\end{array}$ \\
\hline No pain & 0 & 7 & 3 \\
Total with pain & $30(100 \%)$ & $23(76.7 \%)^{*}$ & $27(90 \%)$ \\
\hline
\end{tabular}

* $P=0.0105$ compared with control.

TABLE III VAS pain scores during induction and as recalled in recovery room

\begin{tabular}{llll}
\hline & $\begin{array}{l}\text { Control } \\
(n=30)\end{array}$ & $\begin{array}{l}\text { Lidocaine } \\
(n=30)\end{array}$ & $\begin{array}{l}\text { Thiopentone } \\
(n=30)\end{array}$ \\
\hline OR-VAS (during induction) & $5.6 \pm 2.3$ & $3.3 \pm 2.5^{*}$ & $4.1 \pm 2.7^{*}$ \\
PAR - recall VAS & $5.4 \pm 2.4$ & $4.4 \pm 2.3$ & $4.1 \pm 2.2$ \\
\hline
\end{tabular}

$* P=0.0031$ lidocaine and thiopentone versus control.

TABLE IV Postoperative recall of pain*

\begin{tabular}{lllll}
\hline & & \multicolumn{3}{l}{ Pain during induction } \\
\cline { 2 - 5 } & & No & Yes & Total \\
\hline PAR recall of pain & Yes & 0 & 67 & 67 \\
During induction & No & $\frac{7}{7}$ & $\underline{16}$ & $\underline{23}$ \\
& Total & 7 & 83 & 90 \\
\hline
\end{tabular}

$* P=0.001$ (Fisher's exact test).

93.3\% and $86.2 \%$ respectively for control, lidocaine and thiopentone.

\section{Discussion}

Our study demonstrates that both lidocaine and thiopentone lowered VAS pain scores during propofol induction compared with saline. Lidocaine, but not thiopentone, also reduced the incidence of pain. Neither drug produced amnesia of the pain since the percentage of patients amnestic for pain in the PAR was not different among the three groups studied. In addition, recalled VAS scores in PAR (PAR-recall VAS) were highly correlated with VAS scores in the OR (OR-VAS).

Before reviewing our results it is pertinent to note that previous studies which investigated the problem of propofol injection have varied in their design with respect to: the rate of propofol injection; the timing and method of pain assessment; ${ }^{1-6}$ the use of patient versus observer assessment of pain; 3,4,6 and the use of premedication. $3,4,6$ Factors known to influence the incidence of venous discomfort include: site of $i v$ cannula, speed of injection, speed of intravenous fluid administration, temperature of propofol and pretreatment with sedatives and opioids. ${ }^{1-9}$ Our study design achieved control of these variables.

Various strategies have been investigated to reduce the incidence and severity of propofol injection pain. ${ }^{1-9} \mathrm{Ad}$ ministration of lidocaine, either before or mixed with propofol remains the most widely used method in our institution. ${ }^{1-3}$ Recently, Lee et al. demonstrated that preadministration of $100 \mathrm{mg}$ thiopentone was more effective than lidocaine $20 \mathrm{mg}$ ( $0.5 \%$ solution) in reducing the incidence of propofol injection pain. ${ }^{5}$ Before changing our pattern of practice, it was necessary to confirm the findings of Lee et al.

The most likely explanations for the differences between our results and those of Lee are: (a) Lee used a smaller dose of lidocaine $(20 \mathrm{mg})$ than that used by us (40 mg); however, our dose of lidocaine is in keeping with published guidelines ${ }^{1-3}$; (b) Lee used a larger dose of thiopentone $(100 \mathrm{mg})$ than we did $(50 \mathrm{mg})$. In a pilot evaluation we found that larger doses of thiopentone by being more sedative impaired adequate pain assessment in our patients and precluded the possibility of a doseresponse study. In our study all our patients were awake enough to allow VAS scores to be assessed with a VAS ruler.

The mechanism by which thiopentone reduces pain on injection of propofol is unknown. Even though thiopentone has anti-analgesic properties, ${ }^{10}$ recently it has been demonstrated that, in subhypnotic doses, the combination of thiopentone and propofol produced analgesia 
to experimentally induced pain. ${ }^{11}$ Presumably, venous pain may be reduced by the combined effects of the two drugs. This analgesic effect could be mediated either centrally or peripherally. Since the intensity of venous pain is related to the free aqueous concentration of propofol, ${ }^{12}$ it has been speculated that thiopentone may alter the free aqueous concentration of propofol. ${ }^{5}$

Previous authors have also speculated that inflammation/kinin activation may be important in causing pain with propofol injection. ${ }^{1,7}$ Lidocaine may act by stabilizing the kinin cascade. ${ }^{9}$ Lidocaine has been shown to be more effective if it is mixed with propofol immediately before iv administration. ${ }^{9,13}$ One explanation for this is that in a mixture of lidocaine/propofol, the lidocaine moves into the lipid phase, thereby lowering its free concentration. ${ }^{9}$ The possibility that thiopentone may exert its effects via the kinin cascade cannot be ruled out either.

Recently it has been suggested that venous pain may be due to irritant agents formed when propofol is drawn up in disposable plastic syringes. ${ }^{14}$ Manufacturers have confirmed that propofol strips the silicone lubricant from the inside of the barrel of plastic syringes. ${ }^{14}$ Previously described methods for reducing propofol pain such as cooling to $4^{\circ} \mathrm{C}^{7}$ and diluting the propofol ${ }^{15}$ may presumably slow down or prevent the reaction between propofol and the plastic.

Lee et al. concluded that thiopentone was better than lidocaine in reducing the incidence of propofol injection pain $(P<0.03) .{ }^{5}$ However, they did not adjust their alpha (cut-off level for significance of the $P$ value) to allow for multiple comparisons. In fact, using their data, the adjusted alpha should have been 0.0166 . On the other hand, our study has a power of $85 \%$ to detect a $50 \%$ difference between thiopentone and lidocaine. We would have required a sample size of 108 patients per group to detect a $25 \%$ difference between thiopentone and lidocaine, if one existed. However, our institutional Ethics Committee did not support our continuation of this study for two reasons: (a) A 25\% difference between lidocaine and thiopentone would have little clinical utility and, (b) the incidence of venous pain in our control and thiopentone group was too high to justify continued enrolment of patients on ethical grounds. For practical purposes, both thiopentone and lidocaine are equally effective in reducing the severity of venous pain in the doses used in this study.

The incidence of pain in the lidocaine group was $76.7 \%$ and in the thiopentone group $90 \%$. One reason for the high incidence in these two treatment groups may be a reflection of our study design. We used the Bard ${ }^{\circledR}$ infusion pump to administer the bolus induction dose of propofol at a constant controlled rate to all individuals. This resulted in a slightly prolonged induction time com- pared with our usual clinical practice, but also had the positive effect of allowing adequate time to measure a VAS score during the induction sequence. Results from our study suggest that using this technique may be useful in studying the phenomenon of venous pain with propofol induction. Previous authors have speculated that inflammation/kinin activation may be important in producing the painful response on injection of propofol. ${ }^{1,6}$ The high overall incidence of discomfort with a slow induction technique may be consistent with this hypothesis. Even though the incidence of venous pain was high in all three groups, the VAS scores at the time of induction indicate that both propofol and thiopentone can attenuate propofol injection pain.

In ambulatory outpatients, propofol anaesthesia is associated with a shorter recovery time, earlier resumption of normal activity and less nausea and vomiting. ${ }^{16}$ There may be a concern that pretreatment with thiopentone might prolong recovery time in ambulatory patients. Our study, however, demonstrated that mean discharge times were not different among the three groups.

Minimizing propofol injection pain is an important clinical goal because it may influence the patients' perception of quality and acceptability of anaesthesia. Recall of such discomfort may determine patient's judgement. ' We have demonstrated that recall of venous pain was highly correlated with pain felt during induction. Amnesia for this pain was not produced by thiopentone, lidocaine or propofol. In spite of this, patients' acceptance of propofol for induction was high (89.7\% overall) with no differences among groups. These findings are comparable with those of overall patient satisfaction reported after day surgery by other investigators. ${ }^{17}$

In conclusion, pre-treatment with a small dose of thiopentone $(50 \mathrm{mg})$ was as effective as lidocaine $(40 \mathrm{mg})$ in decreasing the severity of propofol injection pain in ambulatory patients. Lidocaine, however, also reduced the incidence of venous pain. Postoperative recall of venous pain was correlated with pain during injection. Assessing their overall satisfaction, $90 \%$ of ambulatory patients would choose propofol again.

\section{Acknowledgements}

The investigators would like to thank the nursing staff of the Surgical Day Care Centre at Vancouver Hospital and Health Sciences Centre for their help, and Dr. David Parsons and Dr. David Bevan for their helpful comments.

\section{References}

1 King SY, Dovis FM, Wells JE, Murchison DJ, Pryor BJ. Lidocaine for the prevention of pain due to injection of propofol. Anesth Analg 1992; 74: 246-9.

2 Mangar D, Holak EJ. Tourniquet at $50 \mathrm{~mm} \mathrm{Hg}$ followed 
by intravenous lidocaine diminishes hand pain associated with propofol injection. Anesth Analg 1992; 74: 250-2.

3 Gehan G, Karoubi P, Quinet F, Leroy A, Rathat C, Pourriat JL. Optimal dose of lignocaine for preventing pain on injection of propofol. Br J Anaesth 1991; 66: 324-6.

4 Johnson RA, Harper NJN, Chadwick S, Vohra A. Pain on injection of propofol: methods of alleviation. Anaesthesia 1990; 45: 439-42.

5 Lee TW, Lowenthal AE, Strachan JA, Todd BD. Pain during injection of propofol: the effect of prior administration of thiopentone. Anaesthesia 1994; 49: 817-8.

6 Helmers JHJH, Kraaijenhagen RJ, Leeuwen LV, Zuurmond WWA. Reduction of pain on injection caused by propofol (Letter). Can J Anaesth 1990; 37: 267-8.

7 McCrirrick A, Hunter S. Pain on injection of propofol: the effect of injectate temperature. Anaesthesia 1990; 45: 443-4.

8 Hynynen $M$, Korttila $K$, Tammisto $T$. Pain on iv injection of propofol (ICI 35868) in emulsion formulation. Acta Anaesthesiol Scand 1985; 29: 651-2.

9 Scott RPF, Saunders DA, Norman J. Propofol: clinical strategies for preventing the pain of injection. Anaesthesia 1988; 43: 492-4.

10 Briggs LP, Dundee JW, Bahar M, Clarke RSJ.

Comparison of the effects of diisopropyl phenol (ICI 35868) and thiopentone on response to somatic pain. $\mathrm{Br} \mathrm{J}$ Anaesth 1982; 54: 307-11.

11 Anker-Mфller $E$, Spangsberg N, Arendt-Nielsen L, Schultz $P$, Kristensen MS, Bjerring $P$. Subhypnotic doses of thiopentone and propofol cause analgesia to experimentally induced acute pain. Br J Anaesth 1991; 66: 185-8.

12 Klement $W$, Arndt JO Pain on injection of propofol: effects of concentration and diluent. Br J Anaesth 1991; 67: 281-4.

13 Brooker J, Hull CJ, Stafford $M$. Effect of lignocaine on pain caused by propofol injection (Letter). Anaesthesia 1985; 40: 91-2.

14 Lomax D. Propofol injection pain. Anaesth Intensive Care 1994; 22: 500-1.

15 Stokes $D N$, Robson N, Hutton P. Effect of diluting propofol on the incidence of pain on injection and venous sequelae. Br J Anaesth 1989; 62: 202-3.

16 Sung $Y-F$, Reiss $N$, Tillette $T$. The differential cost of anaesthesia and recovery with propofol - nitrous oxide anesthesia versus thiopental sodium - isoflurane - nitrous oxide anesthesia. J Clin Anesth 1991; 3: 391-3.

17 Philip BK. Patient's assessment of ambulatory anesthesia and surgery. J Clin Anesth 1992; 4: 355-8. 